\title{
Tailoring Compressive Strength and Absorption Energy of Lightweight Multi-Phase AlCuSiFeX (X = Cr, Mn, Zn, Sn) High-Entropy Alloys Processed via Powder Metallurgy
}

\author{
Ashutosh Sharma ${ }^{1}\left(\mathbb{D}\right.$, Hansung Lee ${ }^{2}$ and Byungmin Ahn ${ }^{1,2, *(\mathbb{D})}$ \\ 1 Department of Materials Science and Engineering, Ajou University, Suwon 16499, Korea; ashu@ajou.ac.kr \\ 2 Department of Energy Systems Research, Ajou University, Suwon 16499, Korea; lhssung@ajou.ac.kr \\ * Correspondence: byungmin@ajou.ac.kr; Tel.: +82-31-219-3531; Fax: +82-31-219-1613
}

check for

updates

Citation: Sharma, A.; Lee, H.; Ahn, B. Tailoring Compressive Strength and Absorption Energy of Lightweight Multi-Phase AlCuSiFeX ( $X=\mathrm{Cr}$, Mn, $\mathrm{Zn}, \mathrm{Sn}$ ) High-Entropy Alloys Processed via Powder Metallurgy. Materials 2021, 14, 4945. https:// doi.org/10.3390/ma14174945

Academic Editors: Meiqing Zeng and Zhongchen Lu

Received: 5 August 2021

Accepted: 28 August 2021

Published: 30 August 2021

Publisher's Note: MDPI stays neutral with regard to jurisdictional claims in published maps and institutional affiliations.

Copyright: (c) 2021 by the authors. Licensee MDPI, Basel, Switzerland. This article is an open access article distributed under the terms and conditions of the Creative Commons Attribution (CC BY) license (https:// creativecommons.org/licenses/by/ $4.0 /)$.

\begin{abstract}
The development of lightweight HEAs with high strength and low cost is an urgent requirement. In this study, equimolar $\mathrm{AlCuSiFeX}(\mathrm{X}=\mathrm{Cr}, \mathrm{Mn}, \mathrm{Zn}, \mathrm{Sn})$ lightweight HEAs were fabricated by advanced powder metallurgy. The mechanical alloying was performed for $45 \mathrm{~h}$, and the powder compacts were densified at $650^{\circ} \mathrm{C}$. The final results revealed that AlCuSiFeSn lightweight HEA was composed of a single face-centered cubic (FCC) and $\mathrm{Cu}_{81} \mathrm{Sn}_{22}$, whereas AlCuSiFeZn showed a dual FCC and body-centered cubic (BCC) structures. Similarly, AlCuSiFeMn alloy contained a BCC + FCC phase with a $\mu$-phase, whereas a $\sigma$-phase was present in AlCuSiFeCr in addition to FCC + BCC phases. We also calculated various thermodynamic parameters to predict the solidsolution phase stability of each of the above lightweight HEAs. It was found that lightweight HEAs with additive elements $\mathrm{Sn}$ and $\mathrm{Zn}$ tend to predominant FCC phases, whereas those with $\mathrm{Cr}$ and $\mathrm{Mn}$ result in major BCC with hard $\mu$ and $\sigma$ phases, which further improve their mechanical strength. A maximum fracture strain of $23 \%$ was obtained for AlCuSiFeSn followed by $19 \%$ for AlCuSiFeZn HEA. The compressive fracture mechanisms of these lightweight HEAs are also discussed and reported here.
\end{abstract}

Keywords: powder metallurgy; high entropy alloy; lightweight; thermodynamics; absorption energy

\section{Introduction}

High-entropy alloys (HEAs) have become increasingly popular since 2004 and are now well recognized $[1,2]$. Compared with most conventional alloys and steels containing only one principal element, HEAs usually contain five or more principal elements with equiatomic or non-equiatomic compositions varying from 5 to 35 at $\%$ [3,4]. All the principal elements in HEAs contribute equally toward their unique properties that may not be attainable in the traditional alloy design approach $[5,6]$.

Most of the initially developed HEAs include the ductile FCC phase Cantor alloy ( $\mathrm{CrMnFeCoNi}$ ) and its derivatives [7]. A number of these HEAs display remarkable properties, such as high strength [7-11], high ductility [12,13], high fracture toughness [14], and exceptional thermal stability [15]. In contrast, BCC Senkov alloy (TiZrHfNbTa) and refractory HEAs are either very hard or brittle [8,9]. Lightweight HEAs in which the density is close to $7 \mathrm{~g} / \mathrm{cm}^{3}$ have also been actively designed. Youssef et al. designed $\mathrm{Al}_{20} \mathrm{Li}_{20} \mathrm{Mg}_{10} \mathrm{Sc}_{20} \mathrm{Ti}_{30}$ lightweight HEA by cryomilling at subzero temperatures to produce an FCC solid solution phase. After sintering, the bulk lightweight HEA comprised a hexagonal close-packed (HCP) structure with a density of $2.67 \mathrm{~g} / \mathrm{cm}^{3}$ [16]. Other researchers also produced a lightweight $\mathrm{Al}_{20} \mathrm{Be}_{20} \mathrm{Fe}_{10} \mathrm{Si}_{15} \mathrm{Ti}_{35}$ HEA by casting with a density of $3.91 \mathrm{~g} / \mathrm{cm}^{3}$ and hardness of -911 HV [17]. However, most of the lightweight HEAs contain toxic, expensive, and scarce elements [18-20]. Various strengthening mechanisms, such as solid-solution hardening, grain refinement, precipitation hardening, and heterogeneous structure hardening, have been recommended to balance strength and plasticity 
in the existing HEAs [21-25]. However, a lightweight HEA with a good combination of mechanical properties remains a challenging problem.

Compared to the popular arc melting methods for production of HEAs, the powder metallurgy route is now increasingly being considered for $\mathrm{HEAs}$ [26-28]. $\mathrm{Al}_{\mathrm{x}} \mathrm{CoCrFeNi}$ HEAs produced by arc melting and sintering of compacted powder show different microstructures (dendritic, particles, or grains) [29]. A similar study showed the formation of different phases in HEAs produced via powder metallurgy and casting [30]. Some of the cast HEAs, such as AlCoCuZnNi [31], TiFeNiCoCu [32], AlCoCrFeNi [33,34], AlCoCrCuFeNi [35-37], and $\mathrm{CoCrCuFeNiAl0.5} \mathrm{[38],} \mathrm{show} \mathrm{phase} \mathrm{separation} \mathrm{behavior} \mathrm{with}$ unique microstructural properties, crystal structures, and phase separation due to $\mathrm{Cu}$-rich segregates and ordered $\mathrm{L}_{12}$ precipitates $[32,35,38]$.

Powder metallurgy consisting of high-energy ball milling (HEBM) followed by consolidation techniques is widely used to prepare multicomponent alloys and nanomaterials [39]. Advanced spark plasma sintering (SPS) has been widely used to improve the densification rate of resultant bulk HEAs [40]. Recently, equiatomic non-Cantor AlCuSiFeZn HEA produced by HEBM and SPS exhibited a combination of FCC and BCC type solid solutions [41]. Due to the continuous advancement of HEAs in various fields, it is important to understand the various new elemental additions in HEAs. Therefore, this study explores the phase evolution and stability in the processing of AlCuSiFe ( $\mathrm{Zn}, \mathrm{Sn}, \mathrm{Cr}, \mathrm{Mn}$ ) HEAs via HEBM and SPS. We selected (i) $\mathrm{Al}, \mathrm{Cu}, \mathrm{Si}$, and Fe; and (ii) $\mathrm{Cr}$ (BCC), Mn (BCC), Zn (hexagonal close packed, $\mathrm{HCP}$ ), and $\mathrm{Sn}$ (body centered tetragonal, BCT) to prepare a series of lightweight, low cost, and high strength AlCuSiFe (Cr, Mn, Zn, Sn) HEAs. The potential applications of light weight multi-phase $\mathrm{AlCuSiFeX}(X=\mathrm{Cr}, \mathrm{Mn}, \mathrm{Zn}, \mathrm{Sn})$ high entropy alloys include in automotive engine parts, heat exchangers, pipelines and boilers, rocket nozzles, high temperature turbine blades, load bearing components in bridges, and the transportation industry and energy sectors. Lightweight HEAs enable the reduction of both energy consumption and the harmful impact of toxic carbon emissions on the environment. Finally, the microstructure and compressive properties of the HEA alloy systems were systematically investigated.

\section{Materials and Methods}

The elemental powders for the production of lightweight HEAs were $\mathrm{Al}, \mathrm{Cu}$, and $\mathrm{Sn}$, which were $99.9 \%$ pure, whereas $\mathrm{Si}, \mathrm{Fe}, \mathrm{Mn}, \mathrm{Cr}$, and $\mathrm{Zn}$ were $99.8 \%$ pure. These powders in four sets of equiatomic compositions, AlCuSiFe-x ( $x=\mathrm{Zn}, \mathrm{Sn}, \mathrm{Cr}, \mathrm{Mn})$ were HEBMed using a Retsch PM-400 planetary ball mill. The milling media included hardened stainless-steel vial and ball sets. Here, the ball-powder weight ratio was maintained at 10:1 and milling was performed for $45 \mathrm{~h}$. Stearic acid $(0.2 \mathrm{wt} \%)$ was added to the powder mixture to avoid cold welding of the powders.

The HEBMed powders were densified at $50 \mathrm{MPa}$ and $650{ }^{\circ} \mathrm{C}$ using an SPS machine (Dr. Sinter LAB Jr. SPS, Saitama, Japan). The SPS cycle consisted of a heating rate of $100{ }^{\circ} \mathrm{C} / \mathrm{min}$ to $600^{\circ} \mathrm{C}$ and a subsequent rise to $650^{\circ} \mathrm{C}$ at $50^{\circ} \mathrm{C} / \mathrm{min}$ covering a total span of $8 \mathrm{~min}$. The final shape of the product was a compact cylinder $(\varnothing 20 \mathrm{~mm} \times 6 \mathrm{~mm})$. The calculated theoretical densities of lightweight HEAs with $\mathrm{x}=\mathrm{Cr}, \mathrm{Mn}, \mathrm{Zn}$, and Sn were 5.20, $5.23,5.28$, and $5.58 \mathrm{~g} / \mathrm{cm}^{3}$, respectively.

The microstructural characterization of the HEBMed and SPSed samples was performed using a field emission scanning electron microscope (FESEM, JEOL JSM 7500F). The compositional analysis was performed by energy-dispersive X-ray spectroscopy (EDS). To identify the phase structure and evolution, we used a D8 ADVANCE X-ray diffractometer (XRD, $\lambda=1.540598 \AA$ ) operated at $40 \mathrm{kV}$ and $40 \mathrm{~mA}$, where the samples were scanned from $20^{\circ}$ to $80^{\circ}$ in $0.02^{\circ}$ steps.

For compressive strength evaluation, we micromachined the compacts into cylindrical shapes (Ø $3 \mathrm{~mm} \times 6 \mathrm{~mm}$ ). The measurements were carried out on a universal testing machine (Instron 5569 UTM) at a loading rate of $0.1 \% / \mathrm{s}$. The compressive fracture and 
yield stress and absorption energy were determined from the stress-strain diagram. A maximum of five readings were obtained and averaged.

\section{Results and Discussion}

\subsection{Powder Alloying}

The XRD patterns of the AlCuSiFeX (X = Cr, Mn, Zn, Sn) HEAs are shown in Figure 1. The various phases were marked in the XRD patterns. The predominant peaks in the XRD patterns indicate the presence of FCC and BCC solid solutions (Figure 1a). The grinding process occurred separately because of the difference in density and diffusion kinetics of each element during milling. However, up to a certain milling period $(45 \mathrm{~h})$, the grinding process was homogenized due to the increased alloying. A single $B C C$ solid solution phase was formed in AlCuSiFeCr and AlCuSiFeMn HEAs. A dual FCC + BCC solid-solution phase existed in AlCuSiFeZn and AlCuSiFeSn HEAs with the formation of Laves phases. After the inspection of the XRD patterns at higher resolution (Figure 1b), the evolution of dual phase FCC + BCC solid solution phases was conformed. A higher broadening of the peaks in these HEAs indicated the nanocrystallinity of the phases after $45 \mathrm{~h}$ of HEBM.
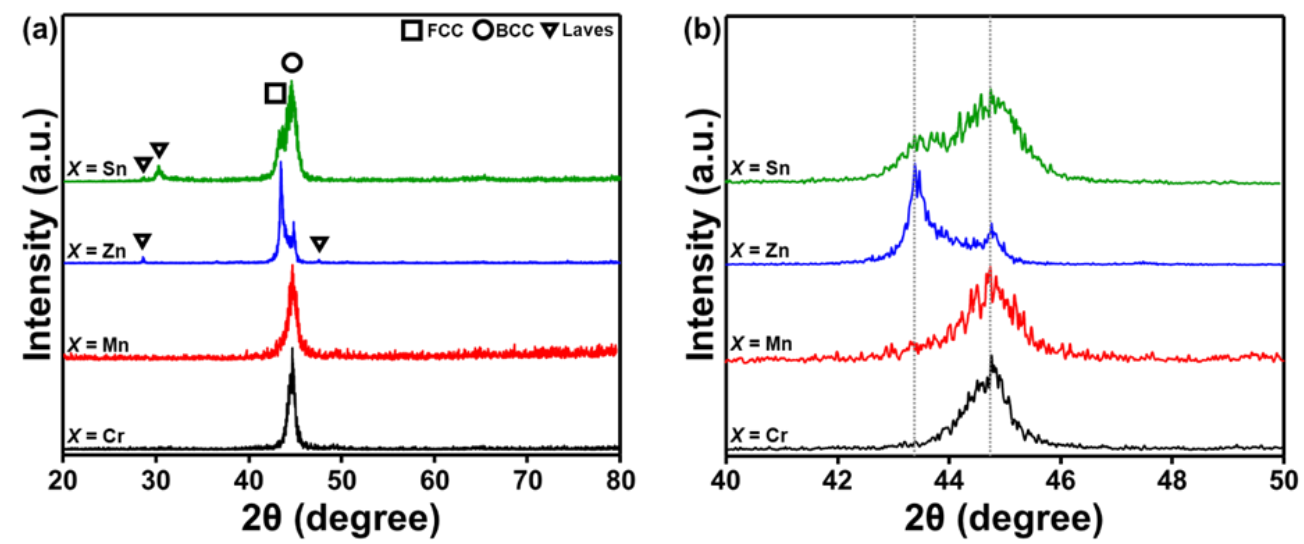

Figure 1. (a) XRD patterns of the HEBMed AlCuSiFeX ( $\mathrm{X}=\mathrm{Cr}, \mathrm{Mn}, \mathrm{Zn}, \mathrm{Sn}) \mathrm{HEAs}$ after $45 \mathrm{~h}$ and (b) the magnified major peak of (a).

According to the study by Guo et al., the FCC phase is stable when valence electron concentration $(V E C) \geq 8$; the $\mathrm{BCC}$ phase is stable when $V E C \leq 6.87$; and $\mathrm{BCC}+\mathrm{FCC}$ phases co-exist when $6.87 \leq V E C \leq 8$ [42]. It can be seen that the $V E C$ criteria (VEC for AlCuSiFeCr: 6.4, AlCuSiFeMn: 6.6, AlCuSiFeZn: 7.6, AlCuSiFeSn: 8) are weaker in AlCuSiFeX (X $=\mathrm{Cr}$, $\mathrm{Mn})$, whereas the microstructure is retained in $\mathrm{AlCuSiFeX}(X=Z n, S n)$. The formation of metastable Laves phases in AlCuSiFeX (X $=\mathrm{Zn}, \mathrm{Sn})$ HEAs was observed. Metastable phases have been observed to form during the HEBM due to the insufficient milling energy available to homogenize the milled powder from the non-equilibrium state $[26,43]$.

\subsection{Spark Plasma Sintered Pellets}

Figure 2 shows the XRD patterns of the SPSed AlCuSiFeX (X = Cr, Mn, Zn, Sn) HEAs at $650{ }^{\circ} \mathrm{C}$. The various crystalline phases are FCC, BCC, $\mu$-, and $\sigma$-phases, and $\mathrm{Cu}_{81} \mathrm{Sn}_{22}$ (Figure 2a). The dominant phases are FCC + BCC + $\sigma$-phase, FCC + BCC + $\mu$-phase, FCC + $\mathrm{BCC}$, and $\mathrm{FCC}+\mathrm{BCC}+\mathrm{Cu}_{81} \mathrm{Sn}_{22}$ phase in $\mathrm{AlCuSiFeX}(\mathrm{X}=\mathrm{Cr}, \mathrm{Mn}, \mathrm{Zn}, \mathrm{Sn})$, respectively. In addition, the Laves phases in AlCuSiFeZn disappeared after HEBM. Table 1 summarizes the various phases formed during HEBM and SPS for comparison. Laves phases disappeared in $\mathrm{AlCuSiFeSn}$ and a new $\mathrm{Cu}-\mathrm{Sn}$ IMC evolved. This may be due to the diffusion of $\mathrm{Cu}$ and Sn atoms during SPS. Due to the high ductility of Sn and its limited solubility in other elements, the segregation of Cu-Sn IMCs is expected in the high entropy system. A similar behavior was also observed by Liu et al. in FeCoCuNiSnx HEAs [44], where the presence of $\mathrm{Cu}_{81} \mathrm{Sn}_{22}$ compound was noticed when $\mathrm{Sn}$ content $>0.05 \%$. 

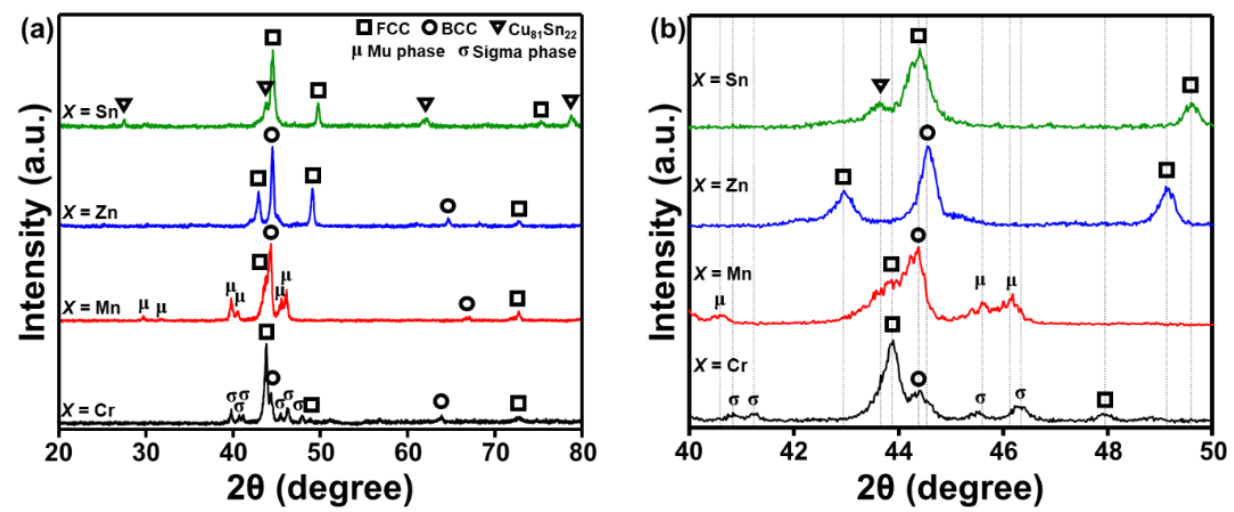

Figure 2. (a) XRD analysis of the SPSed AlCuSiFeX (X = Cr, Mn, Zn, Sn) HEAs and (b) magnified view of (a).

Table 1. Phase evolution after HEBM and SPS from XRD analysis.

\begin{tabular}{|c|c|c|}
\hline \multirow{2}{*}{ Composition } & \multicolumn{2}{|c|}{ Phases } \\
\hline & After HEBM (45 h) & After SPS $\left(650^{\circ} \mathrm{C}\right)$ \\
\hline $\mathrm{AlSiFeCuCr}$ & $\mathrm{BCC}$ & $\mathrm{BCC} / \mathrm{FCC} / \sigma$ \\
\hline AlSiFeCuMn & $\mathrm{BCC}$ & $\mathrm{BCC} / \mathrm{FCC} / \mu$ \\
\hline AlSiFeCuZn & BCC/FCC/Laves & $\mathrm{BCC} / \mathrm{FCC}$ \\
\hline AlSiFeCuSn & BCC/FCC/Laves & $\mathrm{FCC} / \mathrm{Cu}_{81} \mathrm{Sn}_{22}$ \\
\hline
\end{tabular}

As mentioned previously, the VEC of HEAs in the present case falls below 6.87, for $\mathrm{AlCuSiFeCr}$ and $\mathrm{AlCuSiFeMn}$, and thus, the BCC phase is expected. The $V E C$ dual FCC + BCC phase is expected for AlCuSiFeZn, whereas a single FCC phase is expected for $\mathrm{AlCuSiFeSn}$. However, after SPS, the formation of the $\mu$-phase is justified in AlCuSiFeMn, similar to the report of $\mathrm{Wu}$ et al. [45]. Metastable $\sigma$ - and $\mu$-phases were formed in Al$\mathrm{CuSiFeCr}$ and $\mathrm{AlCuSiFeMn} \mathrm{HEAs.} \mathrm{This} \mathrm{result} \mathrm{is} \mathrm{similar} \mathrm{to} \mathrm{those} \mathrm{reports} \mathrm{where} \mathrm{HEAs}$ containing $\mathrm{Cr}$ and $\mathrm{Mn}$ indicate $\sigma$ - and $\mu$-phase formation after SPS [45-47]. It should be noted that HEBM results in the formation of metastable phases that often transform or become stable after SPS. Enhanced enthalpy of nanopowders during HEBM lowers the driving force for the change in phase transformation during SPS [40]. The metastable phases produced during HEBM induce realignment of the grain boundaries and disappearance of crystal defects leads to the formation of new stable phases [40,43].

The density of the investigated HEAs falls within the range of common lightweight alloys. According to the rule of mixture, the density of the investigated $\mathrm{HEAs} \mathrm{AlCuSiFeCr}$, AlCuSiFeMn, AlCuSiFeSn, and AlCuSiFeZn HEAS were 5.2, 5.25, 5.58, and $5.28 \mathrm{~g} / \mathrm{cm}^{3}$, respectively. These values are almost comparable and are in close proximity to those of conventional titanium alloys $\left(4.51-5.75 \mathrm{~g} / \mathrm{cm}^{3}\right)$.

\subsection{Microstructure}

Figure 3 presents SEM images of the various lightweight $\mathrm{AlCuSiFeX} \mathrm{(X=Cr,} \mathrm{Mn,} \mathrm{Zn,}$ Sn) HEAs. Typical equiaxed grain structures were observed in all sintered samples. The HEA matrix was divided into different contrast regions (light and dark), which appeared prominently in the matrix. The results of detailed EDS mapping analysis are shown in Table 2, which indicates the composition of the light- and dark-colored regions. The dark $\mathrm{BCC}$ area corresponds to the Al-Fe-Si phase with 25-27 at\% Al, and the light FCC area corresponds to the $\mathrm{Cu}$-Al-rich phase. The $\mathrm{Cr}$-rich $\sigma$-phase in $\mathrm{AlCuSiFeCr}$ and the Si-rich $\mu$-phase in AlCuSiFeMn were observed (Figure $3 a, b)$ ). For $\mathrm{AlCuSiFeCr}$, the $\mathrm{Cr}$-rich $\sigma$ phase results from the decomposition of the $\mathrm{BCC}$ lattice. A similar observation with different $\mathrm{BCC}$ structures was noted for $\mathrm{Al}_{x} \mathrm{CoCrCoFeNi}(x=0-3.0)[35,38]$. According to the diffraction peaks, the $\mu$-phase was formed in the AlCuSiFeMn HEA. The formation of the $\mu$-phase 
was observed in other reports on Mn-containing HEAs [45]. The AlCuSiFeZn HEA was composed of FCC and BCC solid solutions, whereas AlCuSiFeSn had a single FCC phase with $\mathrm{Cu}_{81} \mathrm{Sn}_{22}$ (Figure 3c,d), which was also confirmed by XRD results.

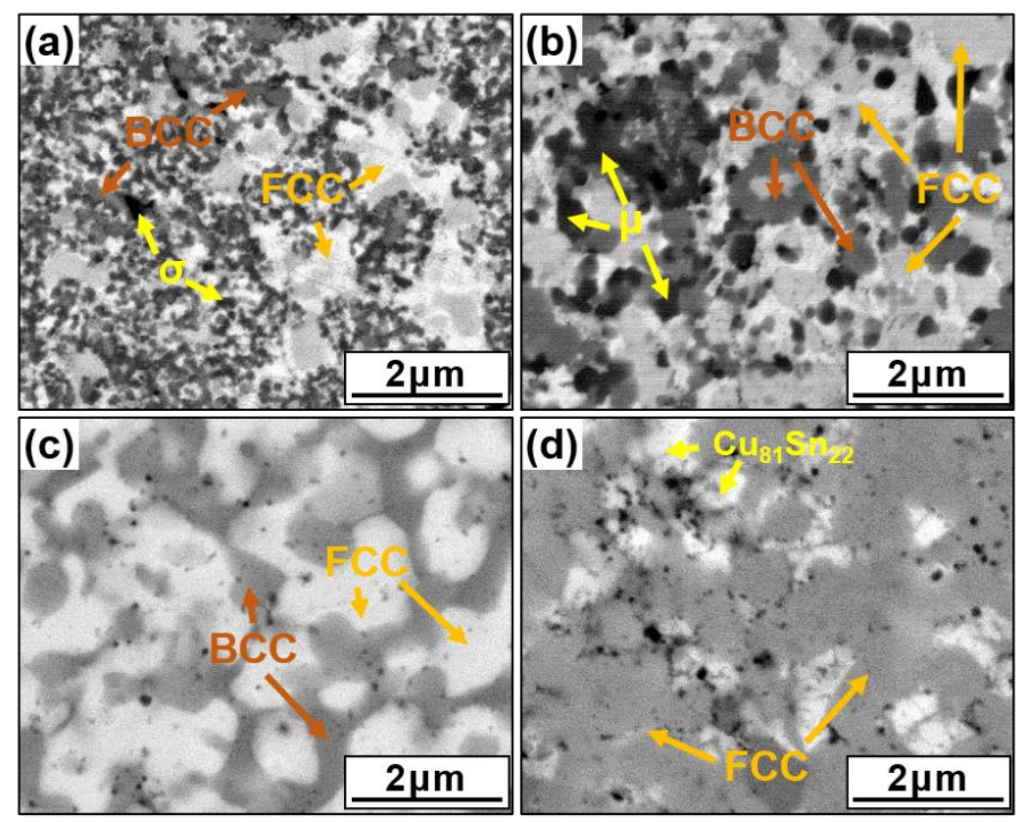

Figure 3. SEM images of the SPSed HEAs. (a) AlCuSiFeCr, (b) AlCuSiFeMn, (c) AlCuSiFeZn, and (d) AlCuSiFeSn.

Table 2. EDS compositional data of the AlSiFeCuX (X = Cr, Mn, Zn, Sn) alloys in at $\%$.

\begin{tabular}{|c|c|c|c|c|c|c|}
\hline HEA & Composition & Al & $\mathrm{Si}$ & $\mathrm{Fe}$ & $\mathrm{Cu}$ & $X$ \\
\hline \multirow{5}{*}{$\mathrm{AlSiFeCuCr}$} & Nominal & 20 & 20 & 20 & 20 & 20 \\
\hline & Actual & 18.23 & 16.22 & 23.32 & 19.58 & 22.65 \\
\hline & FCC & 22.67 & 13.45 & 15.23 & 26.72 & 21.93 \\
\hline & BCC & 27.00 & 24.60 & 15.05 & 10.20 & 23.15 \\
\hline & $\sigma$ & 21.66 & 3.27 & 14.44 & 6.28 & 54.35 \\
\hline \multirow{5}{*}{ AlSiFeCuMn } & Nominal & 20 & 20 & 20 & 20 & 20 \\
\hline & Actual & 18.96 & 16.27 & 16.85 & 28.06 & 19.86 \\
\hline & FCC & 18.71 & 17.16 & 15.13 & 26.64 & 20.36 \\
\hline & $\mathrm{BCC}$ & 27.26 & 26.33 & 14.62 & 7.42 & 14.37 \\
\hline & $\mu$ & 35.23 & 37.32 & 6.61 & 4.68 & 17.16 \\
\hline \multirow{4}{*}{ AlSiFeCuZn } & Nominal & 20 & 20 & 20 & 20 & 20 \\
\hline & Actual & 18.83 & 21.09 & 19.88 & 19.29 & 20.91 \\
\hline & FCC & 10.65 & 11.58 & 19.00 & 33.95 & 24.82 \\
\hline & $\mathrm{BCC}$ & 25.53 & 25.21 & 19.70 & 16.50 & 13.06 \\
\hline \multirow{4}{*}{ AlSiFeCuSn } & Nominal & 20 & 20 & 20 & 20 & 20 \\
\hline & Actual & 24.16 & 16.95 & 17.24 & 25.76 & 15.89 \\
\hline & FCC & 29.59 & 24.35 & 17.02 & 15.11 & 14.93 \\
\hline & $\mathrm{Cu}_{81} \mathrm{Sn}_{22}$ & 5.23 & 4.76 & 8.75 & 65.07 & 16.19 \\
\hline
\end{tabular}

The elemental compositions given in Table 2 indicate Cu-rich FCC and Si-rich BCC phases, and that $\mathrm{Cu}$ undergoes segregation during SPS. Therefore, the $\mathrm{Cu}$ atomic fraction 
in the FCC phase increases to 34 at $\%$, for $\mathrm{x}=\mathrm{Zn}$, whereas in $\mathrm{Cu}_{81} \mathrm{Sn}_{22}$, it increases to over $65 \mathrm{at} \%$ for $\mathrm{x}=\mathrm{Sn}$ (Table 2). The interactions among various elemental segregation and separation behaviors can be identified from the mixing enthalpies of the binary alloy constituents (Table 3).

Table 3. Enthalpy of mixing of binary pairs $(i, j)$ of individual elements $(\mathrm{kJ} / \mathrm{mol})$ of the constituent binary equiatomic HEAs [48].

\begin{tabular}{ccccccccc}
\hline & $\mathbf{A l}$ & $\mathbf{C u}$ & $\mathbf{S i}$ & $\mathbf{F e}$ & $\mathbf{C r}$ & $\mathbf{M n}$ & $\mathbf{Z n}$ & $\mathbf{S n}$ \\
\hline $\mathbf{A l}$ & 0 & -1 & -19 & -11 & -10 & -19 & 1 & 4 \\
\hline $\mathbf{C u}$ & -1 & 0 & -19 & 13 & 12 & 4 & 1 & 7 \\
\hline $\mathbf{S i}$ & -19 & -19 & 0 & -35 & -37 & -39 & -18 & 6 \\
\hline $\mathbf{F e}$ & -11 & 13 & -35 & 0 & -1 & 0 & 4 & 11 \\
\hline $\mathbf{C r}$ & -10 & 12 & -37 & -1 & 0 & 2 & 5 & 10 \\
\hline $\mathbf{M n}$ & -19 & 4 & -39 & 0 & 2 & 0 & -6 & -7 \\
\hline $\mathbf{Z n}$ & 1 & 1 & -18 & 4 & 5 & -6 & 0 & 1 \\
\hline $\mathbf{S n}$ & 4 & 7 & 6 & 11 & 10 & -7 & 1 & 0 \\
\hline
\end{tabular}

The mixing enthalpies between the binary pairs of $\mathrm{Cu}$ and $\mathrm{Al}, \mathrm{Fe}, \mathrm{Si}, \mathrm{Cr}, \mathrm{Mn}, \mathrm{Zn}$, and Sn are $-1,13,-19,12,4,1$, and $7 \mathrm{~kJ} / \mathrm{mol}$, respectively. Similarly, the mixing enthalpies between $\mathrm{Al}$ and $\mathrm{Cu}, \mathrm{Si}, \mathrm{Fe}, \mathrm{Cr}, \mathrm{Mn}, \mathrm{Zn}$, and $\mathrm{Sn}$ are $-1,-19,-11,-10,-19,1$, and $4 \mathrm{~kJ} / \mathrm{mol}$, respectively. This means that $\mathrm{Al}$ attracts $\mathrm{Fe}, \mathrm{Si}, \mathrm{Mn}$, and $\mathrm{Cr}$ to the $\mathrm{BCC}$ area. Due to the positive mixing enthalpy of $\mathrm{Cu}-\mathrm{Zn}(1 \mathrm{~kJ} / \mathrm{mol}), \mathrm{Cu}-\mathrm{Sn}(7 \mathrm{~kJ} / \mathrm{mol}), \mathrm{Cu}-\mathrm{Cr}(12 \mathrm{~kJ} / \mathrm{mol})$, and $\mathrm{Cu}-\mathrm{Mn}(4 \mathrm{~kJ} / \mathrm{mol})$, these are segregated toward the FCC region. However, the high negative mixing enthalpies of $\mathrm{Al}-\mathrm{Si}(-19 \mathrm{~kJ} / \mathrm{mol})$ and $\mathrm{Al}-\mathrm{Fe}(-11 \mathrm{~kJ} / \mathrm{mol})$ attract $\mathrm{Fe}$ and $\mathrm{Si}$ to the $\mathrm{BCC}$ regions.

\subsection{Thermodynamic Analysis}

The thermodynamic parameters of HEAs, such as the atomic size difference $(\delta)$, mixing enthalpy $\left(\Delta H_{\text {mix }}\right)$, mixing entropy $\left(\Delta S_{\text {mix }}\right)$, electronegativity difference $(\Delta \chi)$, and valence electron concentration $(V E C)$, are determined as follows [49-52]:

$$
\begin{array}{r}
\delta=\sqrt{\sum_{i=1}^{n} c_{i}\left(1-\frac{r_{i}}{r}\right)^{2}} \times 100 \\
\Delta H_{\text {mix }}=4 \sum_{i=1, \sum_{i \neq j}^{n} \Delta H_{i j}^{m i x} c_{i} c_{j}} \\
\Delta S_{\text {mix }}=-R \sum_{i=1}^{n} c_{i} \ln c_{i} \\
\Delta \chi=\sqrt{\sum_{i=1}^{n} c_{i}\left(\chi_{i}-\chi\right)^{2}} \\
V E C=\sum_{i=1}^{n} c_{i} V E C_{i}
\end{array}
$$

where $n=5, c_{i}$ and $c_{j}$ indicate concentration in at $\%$ of the $i$ th and $j$ th elements, respectively, and $r_{i}=$ atomic size of the ith element. $r$ and $\chi$ are the mean atomic size and electronegativity of all the elements, respectively. $\Delta H_{m i x}, i j$ is the mixing enthalpy of equiatomic $(i, j)$ alloys. $R=8.314 \mathrm{~J} / \mathrm{mol} \cdot \mathrm{K}$ is the universal gas constant. Yang's interaction parameter is given by:

$$
\Omega=\frac{T_{m} \Delta S_{m i x}}{\left|\Delta H_{m i x}\right|}
$$




$$
T_{m}=\sum_{i=1}^{n} c_{i}\left(T_{m}\right)_{i}
$$

For phase stability, Yang's interaction parameter $\Omega \geq 1.1$ with $\delta \leq 6.6 \%$; Tm is the mean temperature of the HEA. Wang et al. [53] defined another interaction parameter similar to that of Yang [49] for equiatomic HEAs, given by:

$$
\begin{gathered}
\varphi \geq \frac{1.1}{k_{n}}=\varphi_{n} ; \quad \Omega=\frac{k_{n} T_{\text {tot }}}{\left|H_{\text {tot }}\right|}=k_{n} \varphi \\
\Delta H_{\text {mix }}=4 \frac{H_{\text {tot }}}{n^{2}} \\
H_{\text {tot }}=\sum_{i=1, i \neq j}^{n} \Delta H_{i j}^{\text {mix }}
\end{gathered}
$$

$H_{\text {tot }}$ is the total enthalpy of binary pairs of individual elements and $n$ is the number of elements. The coefficient $k$ is a function of $n$. For $n=5, k_{5}$ is fixed. $T_{\text {tot }}$ is the sum of elemental melting points of the HEA $\left(\sum_{i=1}^{n}\left(T_{m}\right)_{i}\right.$. The various thermodynamic parameters $\left(\varphi, \varphi_{5}, k_{5}, \Omega\right)$ were estimated. The parameters for AlCuSiFeX $(\mathrm{X}=\mathrm{Cr}, \mathrm{Mn}, \mathrm{Zn}, \mathrm{Sn})$ are summarized in Figure $4 \mathrm{a}-\mathrm{d}$. Inspection of Figure $4 \mathrm{a}-\mathrm{b}$ shows that the parameter $\varphi \geq \varphi_{5}$ for all $\mathrm{X}(\mathrm{X}=\mathrm{Cr}, \mathrm{Mn}, \mathrm{Zn}, \mathrm{Sn})$ favors solid-solution formation. This observation is consistent with the results of Wang [53].
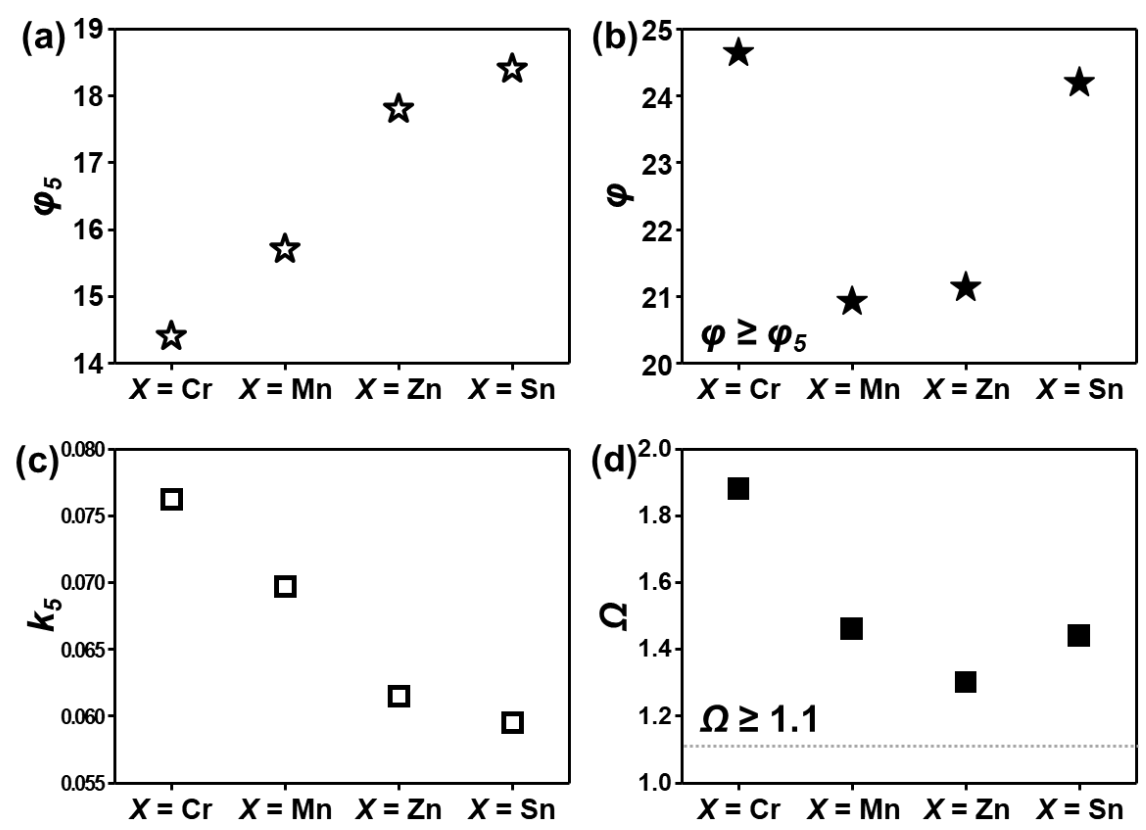

Figure 4. Various thermodynamic parameters (a-d) calculated for AlCuSiFeX (X $=\mathrm{Cr}, \mathrm{Mn}, \mathrm{Zn}$, Sn) HEAs.

In this study, for five component alloys, $\varphi \geq \varphi_{5}=14.3$ favors the formation of solid solution and theoretically $k_{5}=0.057-0.076$ (Figure $4 \mathrm{c}$ ). However, the presence of the $\mu$ phase in $\mathrm{AlCuSiFeMn}$ and the $\sigma$-phase in $\mathrm{AlCuSiFeCr}$ HEAs shows that Yang's interaction parameter is a necessary condition but not essential for the stable solid-solution phase. Additionally, it can be verified by the interaction parameter that $\mathrm{Cr}$ - and $\mathrm{Mn}$-containing HEAs satisfy the criterion of the $\Omega$ parameter (Figure $4 \mathrm{~d}$ ). According to the phase-formation map of $\Omega$ and $\delta$ for the HEAs given by Yang [49], large values of the $\Omega$ parameter and a large atomic size mismatch cause severe lattice distortion and precipitation of ordered compounds is observed. It is noteworthy that the $V E C$ rule does not hold well when the HEA is composed of immiscible elements. In this case, the different elements mix and then 
separate from one another, and the effect of VEC may be significantly weaker [52]. Such contradictions may also be correlated to the different processing conditions compared with those of Guo [42], who studied cast HEAs.

\subsection{Mechanical Properties}

The microhardness and various compressive properties, for example, YS, compressive fracture and yield stress, fracture strain, and absorption energies recorded for lightweight $\mathrm{AlCuSiFeX}(\mathrm{X}=\mathrm{Cr}, \mathrm{Mn}, \mathrm{Zn}, \mathrm{Sn}) \mathrm{HEAs}$ are shown in Figure $5 \mathrm{a}-\mathrm{d}$. The engineering stress and strain curves are also displayed in Figure 5 a.
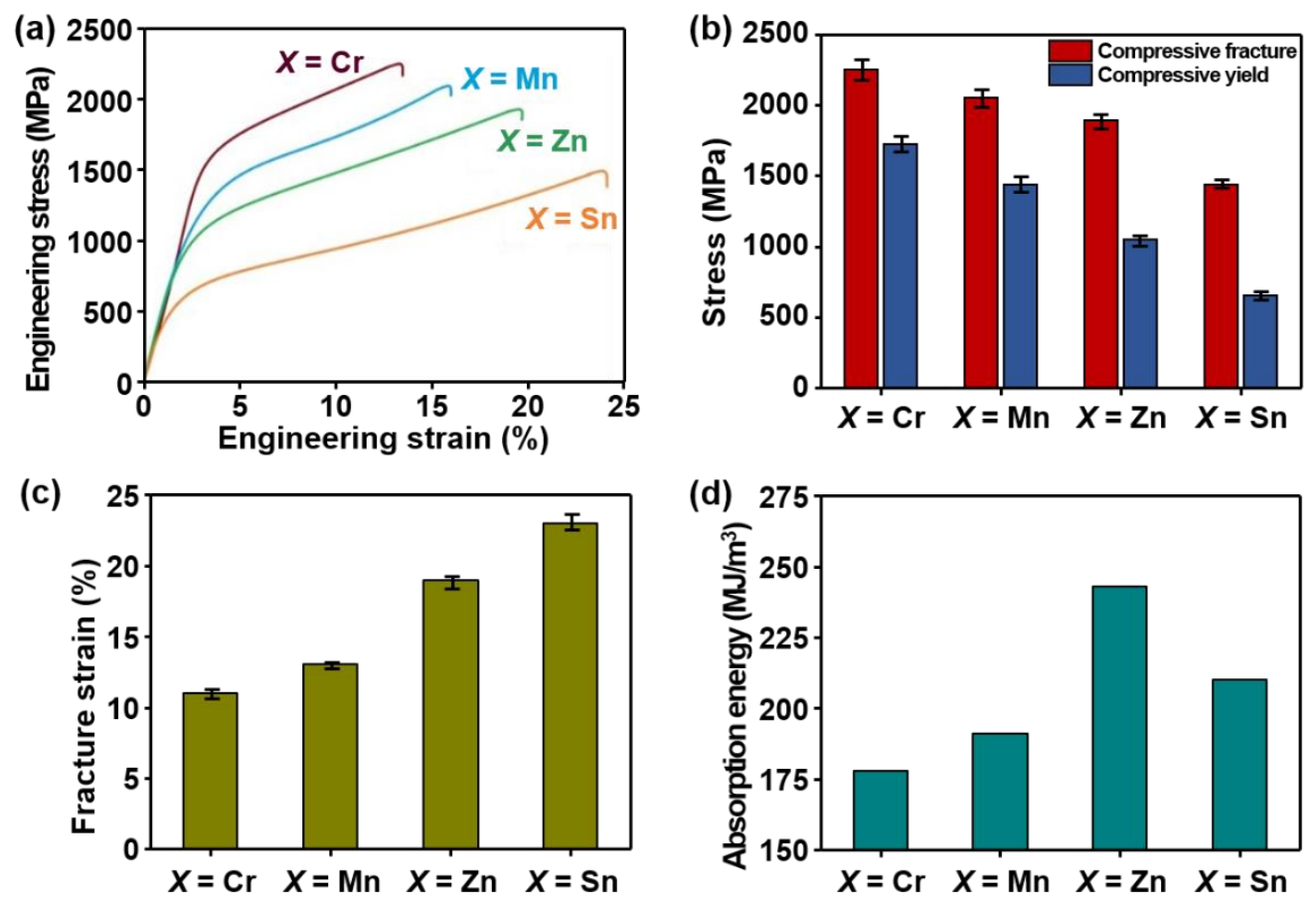

Figure 5. (a) Engineering stress-strain curve, (b) compressive fracture and yield stress, (c) fracture strain, and (d) absorption energy recorded from stress strain curves for AlCuSiFeX (X = Cr, Mn, Zn, Sn) HEAs.

It can be seen that $\mathrm{AlCuSiFeSn-}$ and $\mathrm{AlCuSiFeZn-based} \mathrm{lightweight} \mathrm{HEAs} \mathrm{exhibit} \mathrm{a}$ high plastic region compared to $\mathrm{AlCuSiFeCr}$ and $\mathrm{AlCuSiFeMn} \mathrm{HEAs} \mathrm{(Figure} \mathrm{5a).} \mathrm{Similarly,}$ the compressive yield stress of the AlCuSiFeX HEAs was in the range of 650-1600 MPa. The compressive fracture stress of the AlCuSiFeX HEAs was in the range of 1350-2100 MPa (Figure $5 \mathrm{~b}$ ). The maximum compressive fracture and yield stress were obtained for the $\mathrm{AlCuSiFeCr} \mathrm{HEA}$ at $2080 \mathrm{MPa}$ and $1570 \mathrm{MPa}$, respectively. A maximum elongation of $23 \%$ was obtained for $\mathrm{AlCuSiFeSn}$, followed by $19 \%$ for AlCuSiFeZn (Figure 5c). The results show that the addition of $\mathrm{Zn}$ and $\mathrm{Sn}$, compared with those of $\mathrm{Cr}$ and $\mathrm{Mn}$, significantly enhanced the elongation. In contrast, the ultimate strain was minimal for $\mathrm{AlCuSiFeCr}$ and AlCuSiFeMn. Similarly, the absorption energies of these HEAs follows the trend in the order AlCuSiFeZn > AlCuSiFeSn > AlCuSiFeMn > AlCuSiFeCr. The absorption energy of $\mathrm{AlCuSiFeSn}\left(215 \mathrm{MJ} / \mathrm{m}^{3}\right)$ is slightly lower than AlCuSiFeZn $\left(245 \mathrm{MJ} / \mathrm{m}^{3}\right)$. This can be due to the presence of $\mathrm{Cu}_{81} \mathrm{Sn}_{22}$ IMCs. In contrast, the absorption energies of $\mathrm{AlCuSiFeCr}$ $\left(176 \mathrm{MJ} / \mathrm{m}^{3}\right)$ and AlCuSiFeMn $\left(188 \mathrm{MJ} / \mathrm{m}^{3}\right)$ were minimal. This can be ascribed to the presence of harder phases in the HEAs, such as brittle $\mu$ - and $\sigma$-phases, which increase the strength at the cost of ductility.

The increased solution hardening effect in such dual-phase HEAs may be due to the difference in coordination number (12 for FCC and 8 for BCC), which leads to a larger 
fraction of atomic pairs with dissimilar atoms [2]. The high ductility of FCC-based alloys can be rationalized using the Hollomon equation [54,55]:

$$
\sigma=K \varepsilon^{n}, \text { where } n \text { can be expressed as } n=d\left(\frac{\ln \sigma}{\ln \varepsilon}\right)
$$

Differentiating (11), the Crussard-Jaoul (C-J) equation can be used to study the hardening behavior:

$$
\ln \left(\frac{d \sigma}{d \varepsilon}\right)=\ln (K n)+(n-1) \ln \varepsilon
$$

The Swift model presents the modified (C-J) equation according to the strain and stress equation as follows:

$$
\varepsilon=\varepsilon^{0}+c \sigma^{m}
$$

where $\varepsilon^{0}$ and $c$ are the material constants. The value of $m$ can be extracted by differentiating Equation (11):

$$
\ln \left(\frac{d \sigma}{d \varepsilon}\right)=(1-m) \ln \sigma-\ln c m
$$

In Equations (11)-(14), we can see that the strain hardening increases with increasing strain, i.e., for each case with slopes $(n, n-1,1-m)$. The hardening mechanism of such HEAs proceeds in two steps. Initially, at smaller strains, the deformation is mild from plastic (FCC) to mixed ductile-brittle deformation (FCC, BCC). The FCC phase carries most of the load and transfers it to the other secondary phases (BCC, precipitates). Furthermore, at higher strains, deformation of both FCC and BCC, and elastic deformation of precipitates take place, thereby creating a high density of geometrically necessary dislocations to improve the strain hardening. This behavior is similar to that of dual-phase steels with a soft ferrite phase and a hard martensite phase $[55,56]$.

\subsection{Fracture Analysis}

The fracture morphologies and EDS mapping analysis of the compressive-tested samples are shown in Figure 6. We can see that the fractured surface of AlCuSiFeCr HEAs is quite smooth with a brittle $\mathrm{Cr}$-rich $\sigma$-phase indicating a brittle surface cleavage plane (Figure 6Aa). The fractured surface showed $\mathrm{Cr}$-rich pits during failure (Figure 6Ad, marked with yellow arrows). The SEM image shows that the Si-Cr-rich debris has a sharp faceted structure. In contrast, the fracture surface of $\mathrm{AlCuSiFeMn}$ has some powdery loose $\mathrm{Mn}-\mathrm{Si}$ rich debris and fine microcracks, showing a mixed ductile brittle failure (Figure 6Ba-Bd). The debris shows two types of compositions, namely, the Si-rich and Mn-rich $\mu$-phase. The presence of various microcracks that may have been generated during the compressive crushing of the brittle $\mu$-phase represents an intergranular failure of the HEA (Figure 6Bb, marked with yellow arrows).

There are several globular flakes and smooth regions created in AlCuSiFeZn during the evaporation and degassing of $\mathrm{Zn}$. There is also a signficant presence of $\mathrm{Cu}$ and $\mathrm{Zn}$ in the globular flakes (encircled regions), which are engraved by hard Si-rich phases, and the smooth surface is rich in $\mathrm{Si}$ (Figure $6 \mathrm{Ca}-\mathrm{Cd}$ ). Some chipped out regions are also present, indicating a mixed ductile type failure. The composition of this chipped region was high in Zn indicating intergranular fracture. 

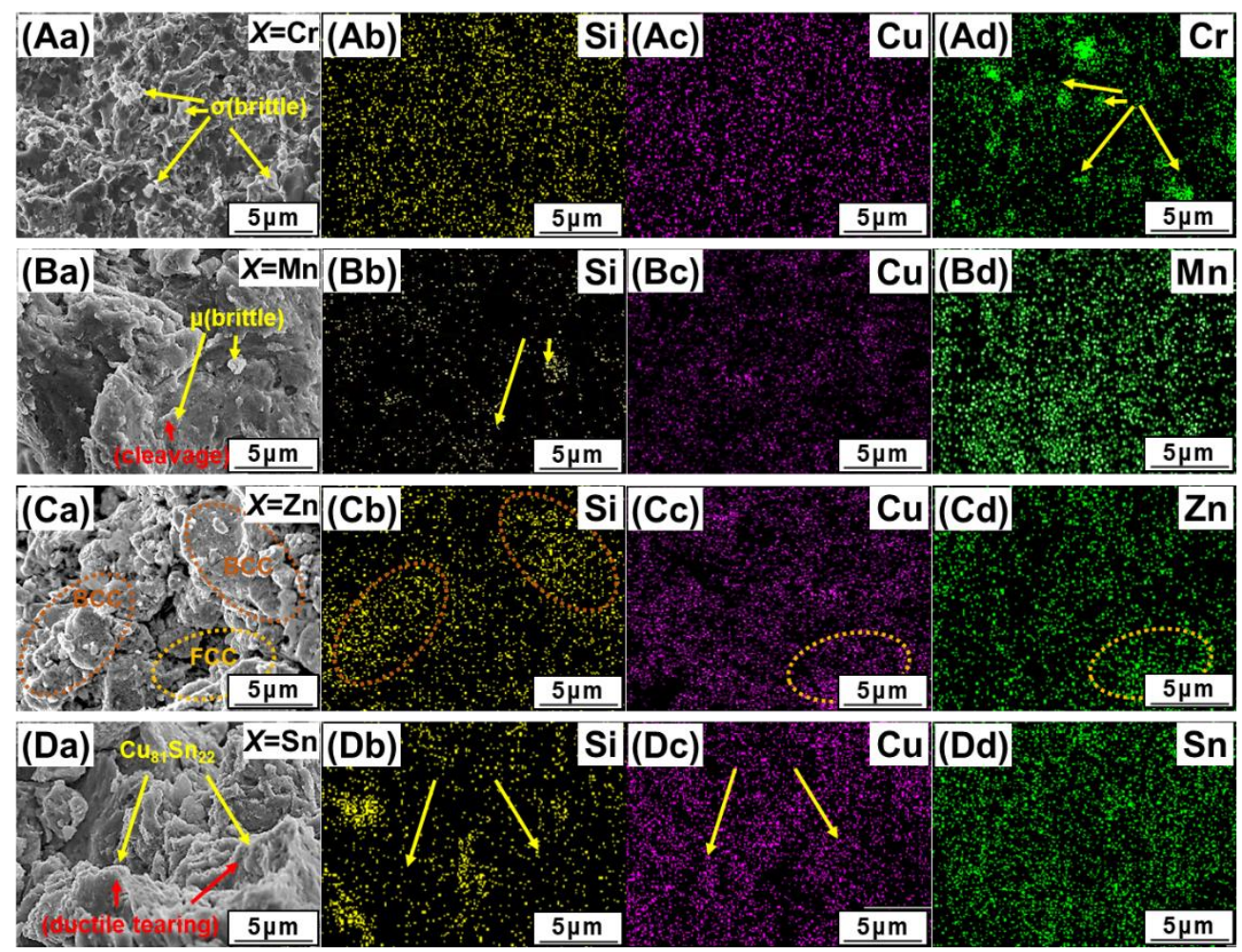

Figure 6. SEM-EDS study of the compressive fracture surfaces of (Aa) $\mathrm{AlCuSiFeCr},(\mathbf{B a}) \mathrm{AlCuSiFeMn}$, (Ca) AlCuSiFeZn, (Da) AlCuSiFeSn HEAs. The corresponding EDS maps are shown in (Ab-Ad, Bb$\mathrm{Bd}, \mathrm{Cb}-\mathrm{Cd}, \mathrm{Db}-\mathrm{Dd})$.

Similarly, Cu-rich particles and Si-Cu-Sn facets were formed in AlCuSiFeSn HEAs. A mixed brittle and ductile type failure, with a number of rough quasi-cleavage planes and slip lines, were observed in the AlCuSiFeSn HEA (Figure 6Db,Dc, marked with yellow arrows), indicating a typical cleavage fracture and slip formation. The slip formation is generally associated with the plastically deformed FCC phase separated by a mild ductility $\mathrm{Cu}_{81} \mathrm{Sn}_{22}$ phase. The cleavage facets are rich in Si. This type of mixed ductile and brittle failure was also previously observed in Si-based HEAs [41]. Therefore, the overall deformation mechanism of $\mathrm{AlCuSiFeX}(\mathrm{X}=\mathrm{Cr}, \mathrm{Mn}, \mathrm{Zn}, \mathrm{Sn}) \mathrm{HEAs}$ comprises loose debris generation, faceted cleavage formation, and slip separation of the phases.

\section{Conclusions}

We prepared a set of lightweight multi-phase HEAs, $\mathrm{AlCuSiFeX}(\mathrm{X}=\mathrm{Cr}, \mathrm{Mn}, \mathrm{Zn}, \mathrm{Sn})$ by HEBM followed by SPS. The microstructural observations showed that the $\mathrm{AlCuSiFeCr}$ alloy consisted of a dominant BCC phase and a minor FCC phase with a $\sigma$-phase, whereas $\mathrm{AlCuSiFeMn}$ consisted of a dominant BCC phase and a minor FCC phase with a $\mu$-phase. Similarly, AlCuSnFeZn showed dual BCC and FCC phases, whereas AlCuSiFeSn showed a single FCC phase with $\mathrm{Cu}_{81} \mathrm{Sn}_{22}$. It was shown that the mixing enthalpies of individual binary alloys play a key role in phase-formation and separation behavior in these HEAs. The thermodynamic analysis shows that our results also conform to the interaction parameters for equiatomic alloys proposed by Yang and Wang for the phase stability of equiatomic HEAs.

Compressive studies show that the values for the compressive yield and fracture stress, and fracture strain of the AlCuSiFeX $(X=\mathrm{Cr}, \mathrm{Mn}, \mathrm{Zn}, \mathrm{Sn})$, follow the order of $\mathrm{X}=\mathrm{Cr}>\mathrm{Mn}>\mathrm{Zn}>\mathrm{Sn}$. However, the fracture strain of these HEAs shows the reverse trend. The maximum elongation (23\%) was observed in AlCuSiFeSn, followed by 19\% in AlCuSiFeZn. The absorption energy of these lightweight AlCuSiFeX ( $\mathrm{X}=\mathrm{Cr}, \mathrm{Mn}, \mathrm{Zn}$, $\mathrm{Sn}$ ) HEAs follows the order of $\mathrm{X}=\mathrm{Zn}>\mathrm{Sn}>\mathrm{Mn}>\mathrm{Cr}$. The mechanism of failure of the $\mathrm{AlCuSiFeX}(\mathrm{X}=\mathrm{Cr}, \mathrm{Mn}, \mathrm{Zn}, \mathrm{Sn}) \mathrm{HEAs}$ depends upon the phase-formation behavior 
in HEAs. A failure mechanism of cleavage fracture and crack formation was present in $\mathrm{AlCuSiFeCr}$, whereas loose powder debris type failure was evident in $\mathrm{AlCuSiFeMn}$. In $\mathrm{AlCuSiFeZn}$ and $\mathrm{AlCuSiFeSn}$, mixed ductile and brittle fractures with quasi-cleavage fracture and slip formation were observed.

Author Contributions: Conceptualization, A.S.; methodology, H.L.; formal analysis and investigation, A.S., H.L.; writing-original draft preparation, A.S.; writing-review and editing, A.S., H.L., B.A.; project administration, B.A.; funding acquisition, A.S., B.A. All authors have read and agreed to the published version of the manuscript.

Funding: This work was supported by the National Research Foundation of Korea (NRF) grant funded by the Korea government (MSIT) (No. 2021R1A2C1005478), (No. 2021R1A4A1031357), (No. 2021R1F1A1062039).

Institutional Review Board Statement: Not applicable.

Informed Consent Statement: Not applicable.

Data Availability Statement: The data required to reproduce these findings cannot be shared at this time, as the research data are confidential.

Conflicts of Interest: The authors declare no conflict of interest.

\section{References}

1. Yeh, J.W.; Chen, S.K.; Lin, S.J.; Gan, J.Y.; Chin, T.S.; Shun, T.T.; Tsau, C.H.; Chang, S.Y. Nanostructured High-Entropy Alloys with Multiple Principal Elements: Novel Alloy Design Concepts and Outcomes. Adv. Eng. Mater. 2004, 6, 299-303. [CrossRef]

2. Murty, B.S.; Yeh, J.W.; Ranganathan, S. High Entropy Alloys, 1st ed.; Butterworth-Heinemann: London, UK, 2014.

3. Zhang, Y.; Zuo, T.T.; Tang, Z.; Gao, M.C.; Dahmen, K.A.; Liaw, P.K.; Liu, Z.P. Microstructures and properties of high-entropy alloys. Prog. Mater. Sci. 2014, 61, 1-93. [CrossRef]

4. Cantor, B.; Chang, I.T.H.; Knight, P.; Vincent, A.J.B. Microstructural development in equiatomic multicomponent alloys. Mater. Sci. Eng. A 2004, 375-377, 213-218. [CrossRef]

5. Ranganathan, S. Alloyed pleasures: Multimetallic cocktails. Curr. Sci. 2003, 85, 1404-1406.

6. Singh, A.K.; Subramaniam, A. On the formation of disordered solid solutions in multi-component alloys. J. Alloy. Compd. 2014, 587, 113-119. [CrossRef]

7. Li, Z.; Zhao, S.; Ritchie, R.O.; Meyers, M.A. Mechanical properties of high-entropy alloys with emphasis on face-centered cubic alloys. Prog. Mater. Sci. 2019, 102, 296-345. [CrossRef]

8. Senkov, O.; Miracle, D.; Chaput, K.; Couzinie, J. Development and exploration of refractory high entropy alloys-A review. J. Mater. Res. 2018, 33, 3092-3128. [CrossRef]

9. Soni, V.; Senkov, O.N.; Gwalani, B.; Miracle, D.B.; Banerjee, R. Microstructural Design for Improving Ductility of An Initially Brittle Refractory High Entropy Alloy. Sci. Rep. 2018, 8, 8816. [CrossRef] [PubMed]

10. Zhang, M.D.; Zhang, L.J.; Fan, J.T.; Yu, P.F.; Li, G. Anomalous microstructure and excellent mechanical behaviors of (CoCrFeNi)6x-yCrxAly high-entropy alloy induced by $\mathrm{Cr}$ and $\mathrm{Al}$ addition. Mater. Sci. Eng. A 2019, 752, 63-74. [CrossRef]

11. Li, D.Y.; Li, C.X.; Feng, T.; Zhang, Y.D.; Sha, G.; Lewandowski, J.J.; Liaw, P.K.; Zhang, Y. High-entropy Al0.3CoCrFeNi alloy fibers with high tensile strength and ductility at ambient and cryogenic temperatures. Acta Mater. 2017, 123, 285-294. [CrossRef]

12. Cai, Z.; Cui, X.; Jin, G.; Liu, Z.; Zheng, W.; Li, Y.; Wang, L. Microstructure and thermal stability of a Ni-Cr-Co-Ti-V-Al high-entropy alloy coating by laser surface alloying. Met. Mater. Int. 2017, 23, 1012-1018. [CrossRef]

13. Tsai, M.H.; Yeh, J.W. High-Entropy Alloys: A Critical Review. Mater. Res. Lett. 2014, 2, 107-123. [CrossRef]

14. Stepanov, N.D.; Shaysultanov, D.G.; Tikhonovsky, M.A.; Zherebtsov, S.V. Structure and high temperature mechanical properties of novel non-equiatomic Fe-(Co, Mn)-Cr-Ni-Al-(Ti) high entropy alloys. Intermetallics 2018, 102, 140-151. [CrossRef]

15. Wang, W.R.; Wang, W.L.; Wang, S.C.; Tsai, Y.C.; Lai, C.H.; Yeh, J.W. Effects of Al addition on the microstructure and mechanical property of AlxCoCrFeNi high-entropy alloys. Intermetallics 2012, 26, 44-51. [CrossRef]

16. Youssef, K.M.; Zaddach, A.J.; Niu, C.; Irving, D.L.; Koch, C.C. A Novel Low-Density, High-Hardness, High-entropy Alloy with Close-packed Single-phase Nanocrystalline Structures. Mater. Res. Lett. 2014, 3, 95-99. [CrossRef]

17. Tseng, K.; Yang, Y.; Juan, C.; Chin, T.; Tsai, C.; Yeh, J. A light-weight high-entropy alloy Al20Be20Fe10Si15Ti35. Sci. China Technol. Sci. 2018, 61, 184-188. [CrossRef]

18. Chae, M.J.; Lee, H.; Sharma, A.; Ahn, B. Effect of light $(X=M g, S i)$ and heavy $(X=Z n)$ metals on the microstructural evolution and densification of AlCuFeMnTi-X high-entropy alloy processed by advanced powder metallurgy. Powd. Met. 2021, 64, 228-234. [CrossRef]

19. Chae, M.J.; Sharma, A.; Oh, M.C.; Ahn, B. Lightweight AlCuFeMnMgTi High Entropy Alloy with High Strength-to-Density Ratio Processed by Powder Metallurgy. Met. Mater. Int. 2021, 27, 629-638. [CrossRef]

20. Kumar, A.; Gupta, M. An Insight into Evolution of Light Weight High Entropy Alloys: A Review. Metals 2016, 6, 199. [CrossRef] 
21. Fu, Z.; Chen, W.; Wen, H.; Zhang, D.; Chen, Z.; Zheng, B.; Zhou, Y.; Lavernia, E.J. Microstructure and strengthening mechanisms in an FCC structured single-phase nanocrystalline Co25Ni25Fe25Al7.5Cu17.5 high-entropy alloy. Acta Mater. 2016, $107,59-71$. [CrossRef]

22. Gwalani, B.; Choudhuri, D.; Liu, K.; Lloyd, J.T.; Mishra, R.S.; Banerjee, R. Interplay between single phase solid solution strengthening and multi-phase strengthening in the same high entropy alloy. Mater. Sci. Eng. A 2020, 771, 138620. [CrossRef]

23. Qin, G.; Chen, R.; Liaw, P.K.; Gao, Y.; Wang, L.; Su, Y.; Ding, H.; Guo, J.; Li, X. An as-cast high entropy alloy with remarkable mechanical properties strengthened by nanometer precipitates. Nanoscale 2020, 12, 3965-3976. [CrossRef]

24. Wang, Q.; Li, Z.; Pang, S.; Li, X.; Dong, C.; Liaw, P.K. Coherent Precipitation and Strengthening in Compositionally Complex Alloys: A Review. Entropy 2018, 20, 878. [CrossRef] [PubMed]

25. Ma, E.; Wu, X. Tailoring heterogeneities in high-entropy alloys to promote strength-ductility synergy. Nat. Comm. 2019, 10, 5623. [CrossRef] [PubMed]

26. Mane, R.B.; Panigrahi, B.B. Comparative study on sintering kinetics of as-milled and annealed CoCrFeNi high entropy alloy powders. Mater. Chem. Phys. 2018, 210, 49-56. [CrossRef]

27. Zhang, A.; Han, J.; Meng, J.; Su, B.; Li, P. Rapid preparation of AlCoCrFeNi high entropy alloy by spark plasma sintering from elemental powder mixture. Mater. Lett. 2016, 181, 82-85. [CrossRef]

28. Mohanty, S.; Maity, T.N.; Mukhopadhyay, S.; Sarkar, S.; Gurao, N.P.; Bhowmick, S.; Biswas, K. Powder metallurgical processing of equiatomic AlCoCrFeNi high entropy alloy: Microstructure and mechanical properties. Mater. Sci. Eng. A 2017, 679, 299-313. [CrossRef]

29. Cieslak, J.; Tobola, J.; Berent, K.; Marciszko, M. Phase composition of AlxFeNiCrCo high entropy alloys prepared by sintering and arc-melting methods. J. Alloy. Compd. 2018, 740, 264-272. [CrossRef]

30. Kumar, A.; Swarnakar, A.K.; Basu, A.; Chopkar, M. Effects of processing route on phase evolution and mechanical properties of CoCrCuFeNiSix high entropy alloys. J. Alloy. Compd. 2018, 748, 889-897. [CrossRef]

31. Mohanty, S.; Gurao, N.P.; Biswas, K. Sinter ageing of equiatomic $\mathrm{Al}_{20} \mathrm{Co}_{20} \mathrm{Cu}_{20} \mathrm{Zn}_{20} \mathrm{Ni}_{20}$ high entropy alloy via mechanical alloying. Mater. Sci. Eng. A 2014, 617, 211-218. [CrossRef]

32. Mohanty, S.; Samal, S.; Tazuddin, A.; Tiwary, C.S.; Gurao, N.P.; Biswas, K. Effect of processing route on phase stability in equiatomic multicomponent Ti20Fe20Ni20Co20Cu20 high entropy alloy. Mater. Sci. Technol. 2015, 31, 1214-1222. [CrossRef]

33. Wwi, J.; Fu, Z.; Wang, W.; Wang, H.; Zhang, J.; Wang, Y.; Zhang, F. Mechanical alloying synthesis and spark plasma sintering consolidation of CoCrFeNiAl high-entropy alloy. J. Alloy. Compd. 2014, 589, 61-66.

34. Manzoni, A.; Daoud, H.; Völkl, R.; Glatzel, U.; Wanderka, N. Phase separation in equiatomic AlCoCrFeNi high-entropy alloy. Ultramicroscopy 2013, 132, 212-215. [CrossRef] [PubMed]

35. Tong, C.J.; Chen, Y.L.; Chen, S.K.; Yeh, J.W.; Shun, T.T.; Tsau, C.H.; Lin, S.J.; Chang, S.Y. Microstructure characterization of Al x CoCrCuFeNi high-entropy alloy system with multiprincipal elements. Metall. Mater. Trans. A 2005, 36, 881-893. [CrossRef]

36. Wang, Y.P.; Li, B.S.; Fu, H.Z. Solid solution or intermetallics in a high-entropy alloy. Adv. Eng. Mater. 2009, 11, 641-644. [CrossRef]

37. Singh, S.; Wanderka, N.; Murty, B.S.; Glatzel, U.; Banhart, J. Decomposition in multi-component AlCoCrCuFeNi high-entropy alloy. Acta Mater. 2011, 59, 182-190. [CrossRef]

38. Xu, X.D.; Liu, P.; Guo, S.; Hirata, A.; Fujita, T.; Nieh, T.G.; Liu, C.T.; Chen, M.W. Nanoscale phase separation in a fcc-based CoCrCuFeNiAl0.5 high-entropy alloy. Acta Mater. 2015, 84, 145-152. [CrossRef]

39. Suryanarayana, C. Mechanical alloying and milling. Prog. Mater. Sci. 2001, 46, 1-184. [CrossRef]

40. Torralba, J.M.; Alvaredo, P.; Junceda, A.G. High-entropy alloys fabricated via powder metallurgy. A critical review. Powder Met. 2019, 62, 84-114. [CrossRef]

41. Sharma, A.; Oh, M.C.; Ahn, B. Microstructural evolution and mechanical properties of non-Cantor AlCuSiZnFe lightweight high entropy alloy processed by advanced powder metallurgy. Mater. Sci. Eng. A 2020, 797, 140066. [CrossRef]

42. Guo, S.; Ng, C.; Lu, J.; Liu, C.T. Effect of valence electron concentration on stability of fcc or bcc phase in high entropy alloys. J. Appl. Phys. 2011, 109, 103505. [CrossRef]

43. Alcalá, M.D.; Real, C.; Fombella, I.; Trigo, I.; Córdoba, J.M. Effects of milling time, sintering temperature, Al content on the chemical nature, microhardness and microstructure of mechanochemically synthesized FeCoNiCrMn high entropy alloy. J. Alloy. Compd. 2018, 749, 834-843. [CrossRef]

44. Liu, L.; Zhu, J.B.; Zhang, C.; Li, J.C.; Jiang, Q. Microstructure and the properties of FeCoCuNiSnx high entropy alloys. Mater. Sci. Eng. A 2012, 548, 64-68. [CrossRef]

45. Wu, P.; Peng, Z.; Liu, N.; Niu, M.; Zhu, Z.; Wang, X. The Effect of Mn Content on the Microstructure and Properties of CoCrCu0.1Fe0.15Mo1.5MnxNi Near Equiatomic Alloys. Mater. Trans. 2016, 57, 5-8. [CrossRef]

46. Praveen, S.; Murty, B.S.; Kottada, R.S. Alloying behavior in multi-component AlCoCrCuFe and NiCoCrCuFe high entropy alloys. Mater. Sci. Eng. A 2012, 534, 83-89. [CrossRef]

47. Praveen, S.; Murty, B.S.; Kottada, R.S. Phase evolution and densification behavior of nanocrystalline multicomponent high entropy alloys during spark plasma sintering. JOM 2013, 65, 1797-1804. [CrossRef]

48. Takeuchi, A.; Inoue, A. Classification of Bulk Metallic Glasses by Atomic Size Difference, Heat of Mixing and Period of Constituent Elements and Its Application to Characterization of the Main Alloying Element. Mater. Trans. 2005, 46, 2817-2829. [CrossRef]

49. Yang, X.; Zhang, Y. Prediction of high-entropy stabilized solid-solution in multi-component alloy. Mater. Chem. Phys. 2012, 132, 233-238. [CrossRef] 
50. Li, C.; Li, J.C.; Zhao, M.; Jiang, Q. Effect of alloying elements on microstructure and properties of multiprincipal elements high-entropy alloys. J. Alloy. Compd. 2009, 475, 752-757. [CrossRef]

51. Fang, S.; Xiao, X.; Xia, L.; Li, W.; Dong, Y. Relationship between the widths of supercooled liquid regions and bond parameters of Mg-based bulk metallic glasses. J. Noncryst. Solids 2003, 321, 120-125. [CrossRef]

52. Guo, S.; Liu, C.T. Phase stability in high entropy alloys: Formation of solid-solution phase or amorphous phase. Prog. Nat. Sci. 2011, 21, 433-446. [CrossRef]

53. Wang, Z.; Wang, X.; Yue, H.; Shi, G.; Wang, S. Microstructure, thermodynamics and compressive properties of AlCoCrCuMn-x (x=Fe, Ti) high-entropy alloys. Mater. Sci. Eng. A 2015, 627, 391-398. [CrossRef]

54. Hollomon, J.H. Time-temperature relations in tempering steel. Trans. AIME 1945, 162, 223-249.

55. Son, Y.I.; Lee, Y.K.; Park, K.T.; Lee, C.S.; Shin, D.H. Ultrafine grained ferrite-martensite dual phase steels fabricated via equal channel angular pressing: Microstructure and tensile properties. Acta Mater. 2005, 53, 3125-3134. [CrossRef]

56. Saeidi, N.; Karimi, M.; Toroghinejad, M. Development of a new dual phase steel with laminated microstructural morphology. Mater. Chem. Phys. 2017, 192, 1-7. [CrossRef] 